\title{
Effects of hCG administration on corpus luteum development and plasma sex steroid hormone concentration in beef heifers differ according to the locational relationships of the original corpus luteum and the first-wave dominant follicle
}

\author{
Ken HAZANO ${ }^{1,2)}$, Shingo HANEDA ${ }^{2)}$, Mitsunori KAYANO ${ }^{3)}$, Ryotaro MIURA ${ }^{4)}$ and \\ Motozumi MATSUI ${ }^{2) *}$

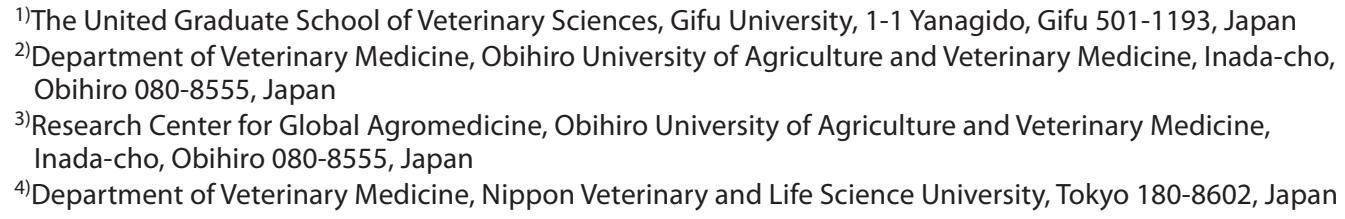

J. Vet. Med. Sci.

82(8): 1219-1225, 2020

doi: 10.1292/jvms.20-0199

Received: 7 April 2020

Accepted: 27 May 2020

Advanced Epub:

24 June 2020
ABSTRACT. The aims of this study were to compare the effects of an intramuscular human chorionic gonadotropin (hCG) administration on corpus luteum (CL) development, plasma progesterone (P4) and estradiol (E2) concentration in ipsilateral (first-wave dominant follicle [W1DF] in the same ovary as the $\mathrm{CL}$ ) and contralateral (W1DF and CL in opposite ovaries) cattle. Cross-bred beef heifers (Holstein $\times$ Japanese black, $n=83$ ) with synchronized ovulation were randomly assigned to either treatment with 1,500 IU hCG or no treatment on day 5 post-ovulation and were subdivided into ipsilateral ( $h$ CG treatment, $n=21$; no treatment, $n=23$ ) or contralateral (hCG treatment, $n=17$; no treatment, $n=17$ ) groups. Five heifers were excluded from the study, as they presented with double ovulation in response to hCG treatment. The effects of hCG treatment, location (ipsilateral and contralateral), and the number of days post-ovulation (days 5,7 , and 14) were analyzed using three-way ANOVA. hCG treatment significantly increased CL diameter on day 7 and plasma P4 concentration on days 7 and 14 in the contralateral group, but not the ipsilateral group. In contrast, hCG treatment decreased plasma E2 concentration on days 7 and 14 in both groups. In summary, our results indicate that the $\mathrm{hCG}$ treatment more significantly promoted CL development and increased plasma P4 concentration in the contralateral than in the ipsilateral group.

KEY WORDS: accessory corpus luteum, first-wave dominant follicle, human chorionic gonadotropin, plasma progesterone

In mammals, corpus luteum (CL) formation is initiated at ovulation by the differentiation of granulosa and theca cells into large and small luteal cells, respectively [1]. The CL secretes progesterone (P4) which is essential for the establishment of pregnancy. P4 regulates the function of various components of the reproductive tract, including the uterus [19, 23]. Plasma P4 concentration after artificial insemination (AI) influences fertility in cattle, with low plasma P4 concentrations resulting in decreased fertility [10, 23]. In contrast, the first follicular wave emerges soon after ovulation, concomitant with CL formation in bovine ovaries. A dominant follicle deviates from the first follicular wave and is, thereafter, referred to as the first-wave dominant follicle (W1DF) [7]. The W1DF produces estradiol (E2) and causes small increases in plasma E2 concentration after ovulation [5, 17]. A high plasma E2 concentration between post-ovulation and the early luteal phase may reduce bovine fertility [2, 15]. Therefore, ovarian function and plasma sex steroid hormone concentrations after ovulation are closely associated with fertility in cattle.

In cattle, intramuscular human chorionic gonadotropin (hCG) administration has an effect resembling that of luteinizing hormone (LH). It induces ovulation and promotes CL development $[9,16]$. The administration of hCG from 5-7 day post-estrus activates the CL, induces W1DF ovulation, promotes the formation of an accessory CL, increases plasma P4 concentration 
$[4,18,21,22]$, and decreases plasma E2 concentration [15] in cattle. Based on the effects of hCG on bovine plasma P4 and E2 concentration, hCG is administered during the early luteal phase to improve the conception rates after AI [14] and embryo transfer (ET) in cattle $[4,6,15,21,22]$. However, the effects of hCG administration on fertility in cattle have not been consistent among various studies.

It was recently reported that the locational relationship between W1DF and CL at the time of hCG administration influences conception rate after the AI of dairy cows [12]. In cases where the W1DF and CL were situated in the same ovary (ipsilateral), hCG administration on day 5 post-AI improved the conception rate. However, this response did not occur when the W1DF and CL were in opposite ovaries (contralateral). These results may indicate that the effects of hCG on endocrine status, which affects fertility in cattle, are different between ipsilateral and contralateral groups. However, there are no studies that have examined the effects of hCG on plasma sex steroid hormone levels considering the positional relationship between the W1DF and CL.

The aims of this study were to examine the effects of intramuscular hCG administration, at day 5 post-ovulation, on CL development and plasma P4 and E2 levels, between cattle with the W1DF and CL in ipsilateral and contralateral locations.

\section{MATERIALS AND METHODS}

This study was approved by the Animal Experiment Committee of Obihiro University of Agriculture and Veterinary Medicine, Japan.

\section{Animal and experimental protocol}

Cross-bred beef heifers ( $\mathrm{n}=83$; Japanese black $\times$ Holstein; 13-19 months old) were used for this study. Heifers were maintained in free barns and fed corn silage plus feed concentrate at a commercial farm in Hokkaido, northeast Japan.

The experimental protocol is illustrated in Fig. 1. The estrous cycles of the heifers were synchronized using a 9-day vaginal insert containing 1.9 g P4 (CIDR; CIDR 1900; Zoetis JP, Tokyo, Japan) and administration of 2 mg estradiol benzoate (EB; Ovahormone ${ }^{\circledR}$ injection; ASKA Animal Health Co., Ltd., Tokyo, Japan). They were also administered 25 mg dinoprost (prostaglandin F2 $\alpha$ [PGF2 $\alpha$ ]; Pronalgon F; Zoetis, Parsippany-Troy Hills, NJ, USA) on the day of CIDR removal. One day after PGF2 $\alpha$ administration, $1 \mathrm{mg}$ EB was injected followed $12 \mathrm{hr}$ later by $100 \mu \mathrm{g}$ of the GnRH analog fertirelin acetate (Spornen; Kyoritsu Seiyaku, Tokyo, Japan). The timed ovulation date was set as day 0 . On day 5 , heifers were randomly assigned to two groups, which were either administered 1,500 IU hCG (Gestron1500; Kyoritsu Seiyaku, Tokyo, Japan; n=43) or received no treatment $(\mathrm{n}=40)$. Transrectal ultrasonography was performed to examine the original CL and W1DF. The follicle with the largest diameter $(>8.0 \mathrm{~mm})$ on day 5 and/or day 7 was designated as the W1DF. For the hCG treatment group, accessory CL formation was confirmed on day 14 . Accessory CL formation was observed in all heifers administered hCG. Five heifers with $>2$ accessory CLs were excluded from the study. Heifers were divided into ipsilateral (hCG treatment, $\mathrm{n}=21$; no treatment, $\mathrm{n}=23$ ) and contralateral (hCG treatment, $\mathrm{n}=17$; no treatment, $\mathrm{n}=17$ ) groups, based on observations of the locational relationship between the original CL and W1DF in the ovary. Embryo transfer was performed on day 7 or 8. Pregnancy was determined using transrectal ultrasonography from days $45-50$. For 56 heifers (ipsilateral group: hCG treatment, $n=15$; no treatment, $n=15$ and contralateral group: hCG treatment, $\mathrm{n}=14$; no treatment, $\mathrm{n}=12$ ), the $\mathrm{CL}$ diameters were measured on days 5 , 7 , and 14 . Blood samples were collected on days 7 and 14 .

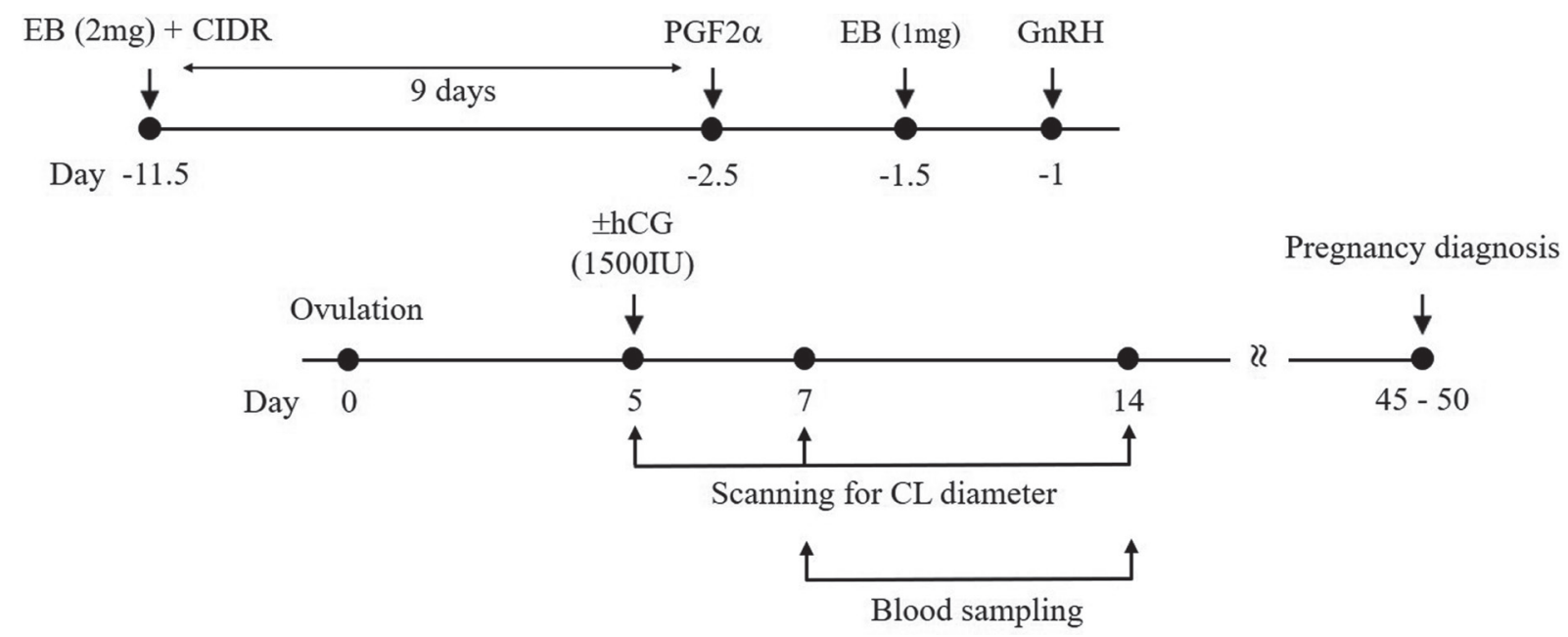

Fig. 1. Experimental protocol. EB, estradiol benzoate; CIDR, controlled internal drug release insert; PGF2 $\alpha$, prostaglandin F2 $\alpha$; hCG, human chorionic gonadotropin; $\mathrm{CL}$, corpus luteum; GnRH, gonadotropin releasing hormone agonist. 


\section{Embryo transfer}

An in vivo frozen-thawed embryo was transferred by the same technician to the deep uterine horn, ipsilateral to the ovary with the original CL, via a bovine embryo/semen deep-injection catheter (YT gun, Yamanetech Co., Ltd., Nagano, Japan) on day 7 or 8.

\section{CL ultrasonography}

Ovaries were examined with a transrectal ultrasonograph fitted with a linear probe emitting a frequency of $5 \mathrm{MHz}$ (HS-101V; Honda Electronics, Toyohashi, Japan). The original CL diameter was measured on days 5, 7, and 14. For the hCG treatment group, the accessory CL diameter was measured on day 14.

\section{Blood sampling and hormone assays}

To measure plasma P4 and E2 levels, on days 7 and 14, blood samples were collected from the coccygeal vein or artery in evacuated heparinized tubes and immediately placed on ice. Blood samples were centrifuged at $2,000 \times \mathrm{g}$ for $20 \mathrm{~min}$ at $4{ }^{\circ} \mathrm{C}$ and the plasma components were separated and stored at $-30^{\circ} \mathrm{C}$ until their use in hormone assays. Plasma P4 and E2 levels were determined in duplicate using a second-antibody enzyme immunoassay (EIA), according to a previously described procedure [13]. Sex steroid hormone assays were performed after extraction with diethyl ether. P4 and E2 recovery rates were $92.3 \%$ and $84.8 \%$, respectively. The EIA standard curve ranged from $0.05-50 \mathrm{ng} / \mathrm{ml}$ and 2-2,000 pg/ml for P4 and E2, respectively. The intra- and inter-assay coefficients of variation (CV) were $6.4 \%$ and $9.6 \%$ for $\mathrm{P} 4$ and $7.6 \%$ and $9.8 \%$ for E2, respectively.

\section{Statistical analysis}

Data are presented as means \pm SEM. For the original CL diameter and plasma P4 and E2 concentrations, the main effects of hCG (hCG vs. no treatment), location (ipsilateral vs. contralateral), and day (CL diameter: day 5 vs. day 7 vs. day 14; plasma P4 and E2 concentrations: day 7 vs. day 14), pairwise interactions (hCG $\times$ location, hCG $\times$ day, location $\times$ day), and three-way interactions $(\mathrm{hCG} \times$ location $\times$ day) were analyzed by three-way ANOVA. When two-way or three-way interactions were detected, the simple main effects were analyzed for each independent variable. Post hoc analysis was performed using a Tukey-Kramer test or Student's $t$-test. The accessory CL diameters in the ipsilateral and contralateral groups under hCG treatment were analyzed by Student's $t$-test. All statistical analyses were performed in StatView v. 5.0 (SAS Institute, Cary, NC, USA). $P<0.05$ was considered statistically significant. Furthermore, $0.05 \leq P<0.1$ was regarded as a tendency.

\section{RESULTS}

\section{Original and accessory CL diameters}

The $P$ values for the main effects and their interactions on the original CL diameter are shown in Table 1. A three-way interaction was observed for the original CL diameter $(P<0.05)$. For the ipsilateral and contralateral groups, the original CL diameters were significantly larger on days 7 and 14 than on day $5(P<0.05$; Fig. 2A and 2B). For the contralateral group, the original CL diameter was larger on day 7 with hCG treatment than with no treatment $(P<0.01 ;$ Fig. $2 \mathrm{~B})$. No difference was observed between ipsilateral heifers with or without hCG treatment (Fig. 2A). There was no difference in original CL diameter between the ipsilateral and contralateral groups under hCG treatment (Fig. 3). Moreover, no difference was observed in accessory CL diameter on day 14 between the ipsilateral and contralateral groups under hCG treatment (Fig. 4).

\section{Plasma P4 and E2 concentrations}

The $P$ values for the main effects and their interactions on plasma P4 concentration are shown in Table 1 . There were hCG $\times$ location $(P<0.01)$ and hCG $\times$ day $(P<0.05)$ interaction effects on plasma $\mathrm{P} 4$ concentration. For the ipsilateral and contralateral groups, P4 concentration was higher on day 14 than day $7(P<0.001$; Fig. 5A and 5B). In the ipsilateral group, P4 concentration was slightly higher with hCG treatment than with no treatment $(0.05 \leq P<0.1$; Fig. $5 \mathrm{~A})$. In contrast, heifers in the contralateral group treated with hCG presented with significantly higher P4 concentrations than those with no treatment $(P<0.001 ; \mathrm{Fig}$. 5B). With hCG treatment, $\mathrm{P} 4$ concentrations were higher in the contralateral group than the ipsilateral group $(P<0.05$; Fig. 6). However, there was no difference in $\mathrm{P} 4$ concentration between the untreated ipsilateral and contralateral groups.

The $P$ values for the main effects and their interactions on plasma E2 concentration are shown in Table 1. There were no interactions among the three main effects on plasma E2 concentration. Plasma E2 concentration was higher on day 7 than day 14 $(P<0.01$; Fig. 7). hCG-treated heifers in both the ipsilateral and contralateral groups had lower E2 levels than untreated heifers $(P<0.01$; Fig. 7). However, there was no difference in plasma E2 levels between the ipsilateral and contralateral groups treated with

Table 1. The effects of hCG treatment, location, and post-ovulation day, with their respective double and triple interactions, on original corpus luteum diameter, plasma progesterone concentration, and estradiol concentration

\begin{tabular}{llcccccc}
\hline \multicolumn{1}{c}{ Dependant variable } & hCG & Location & Day & hCG $\times$ Location & hCG $\times$ Day & Location $\times$ Day & hCG $\times$ Location $\times$ Day \\
\hline CL diameter $(\mathrm{mm})$ & $<0.05$ & NS & $<0.001$ & NS & $<0.01$ & $<0.01$ & $<0.05$ \\
P4 concentration $(n \mathrm{~g} / \mathrm{m} l)$ & $<0.001$ & NS & $<0.001$ & $<0.01$ & $<0.05$ & NS & NS \\
E2 concentration $(p \mathrm{~g} / \mathrm{m} l)$ & $<0.01$ & NS & $<0.01$ & NS & NS & NS & NS \\
\hline
\end{tabular}

Data were analyzed by three-way ANOVA. hCG, human chorionic gonadotropin; CL, corpus luteum; NS, not statistically different; P4, progesterone; E2, estradiol. 

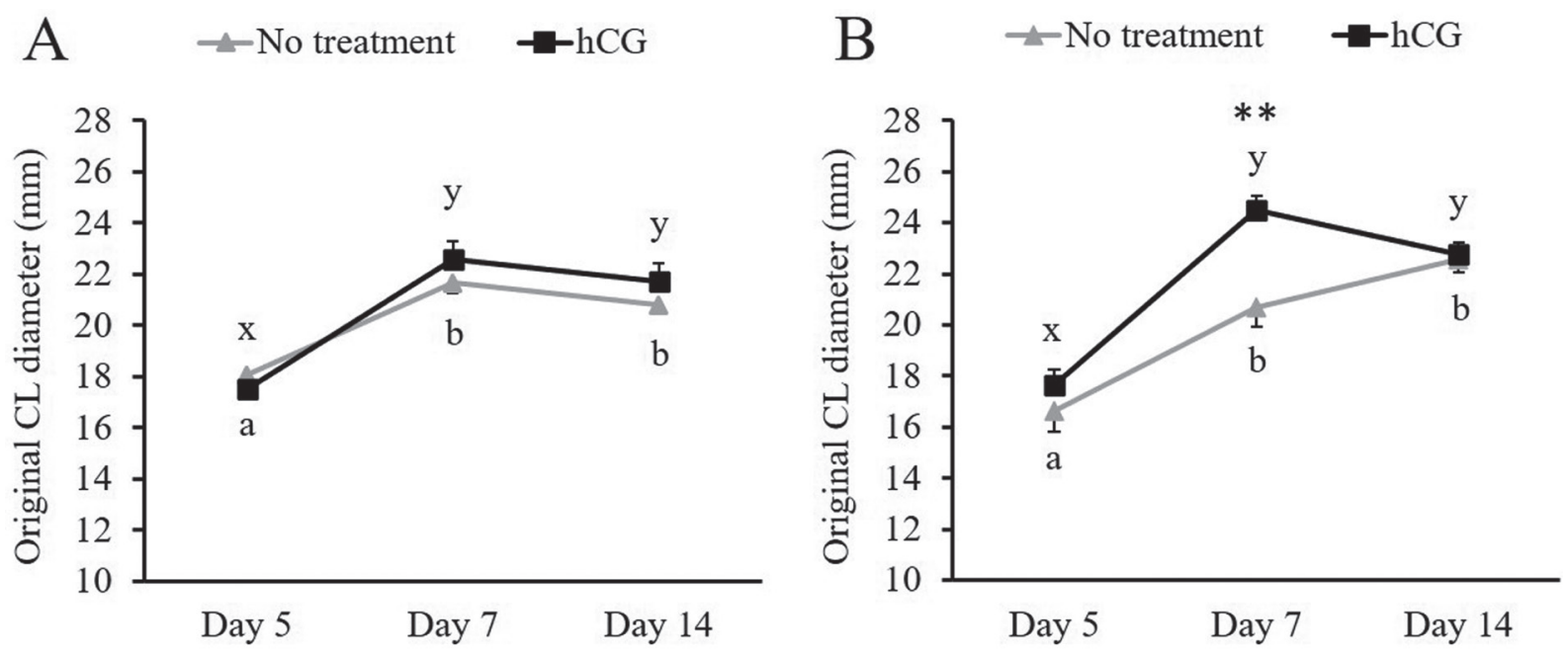

Fig. 2. Original corpus luteum diameters on days 5, 7, and 14 in the hCG-treated or untreated ipsilateral (A) and contralateral (B) groups. Different superscript letters within a and b between days in the untreated group and within $\mathrm{x}$ and $\mathrm{y}$ between days in hCG-treated group indicate significant difference $(P<0.05)$. ${ }^{*} P<0.01$ : significant difference between no treatment and hCG treatment. CL, corpus luteum; hCG, human chorionic gonadotropin.

\section{$\rightarrow$ Ipsilateral $\rightarrow$-Contralateral}

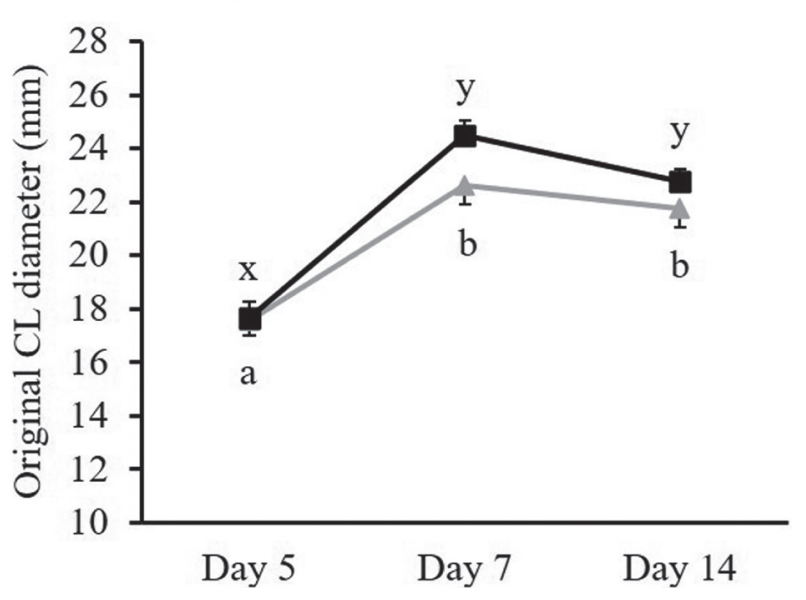

Fig. 3. Original corpus luteum diameters on days 5, 7, and 14 between the hCG-treated ipsilateral and contralateral groups. Different superscript letters within $a$ and $b$ between days in the ipsilateral group and within $\mathrm{x}$ and $\mathrm{y}$ between days in the contralateral group indicate significant differences $(P<0.05)$. CL, corpus luteum.

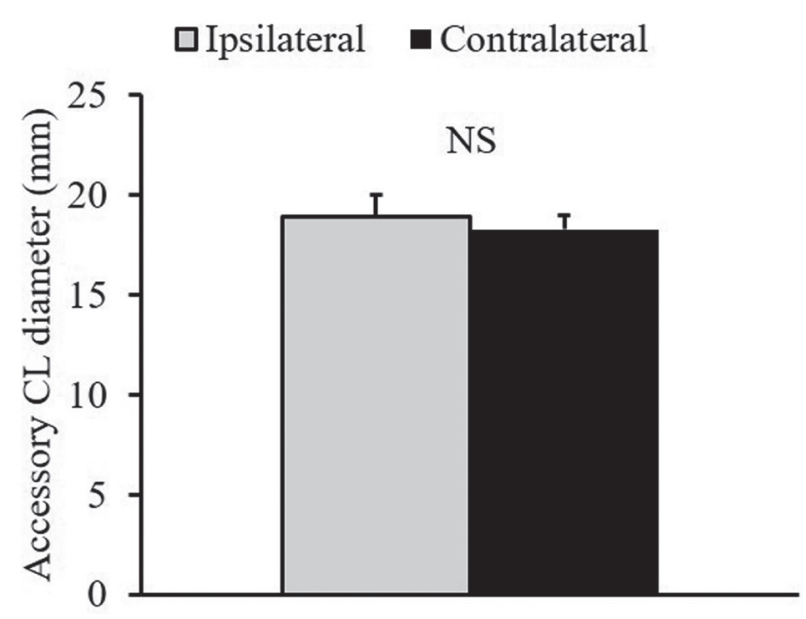

Fig. 4. Accessory corpus luteum diameter on day 14 in the hCGtreated ipsilateral and contralateral groups. NS: not statistically significant; $\mathrm{CL}$, corpus luteum.

hCG. Similarly, there was no difference in E2 levels between untreated ipsilateral and contralateral heifers.

\section{ET conception rate}

The ET conception rates were 70\% (28/40) and 84\% (32/38) in untreated and hCG treatment groups, respectively. Furthermore, the ET conception rates were 70\% (16/23) and 76\% (16/21) for untreated and hCG-treated ipsilateral heifers, respectively and 71\% $(12 / 17)$ and $94 \%(16 / 17)$ for untreated and hCG-treated contralateral heifers, respectively.

\section{DISCUSSION}

The administration of hCG, on day 5 post-ovulation, to contralateral heifers with synchronized ovulation and subjected to ET significantly promoted original CL development and increased plasma P4 concentration. In contrast, hCG administration had no significant effect on these parameters in ipsilateral heifers. 
A

$\square$ No treatment

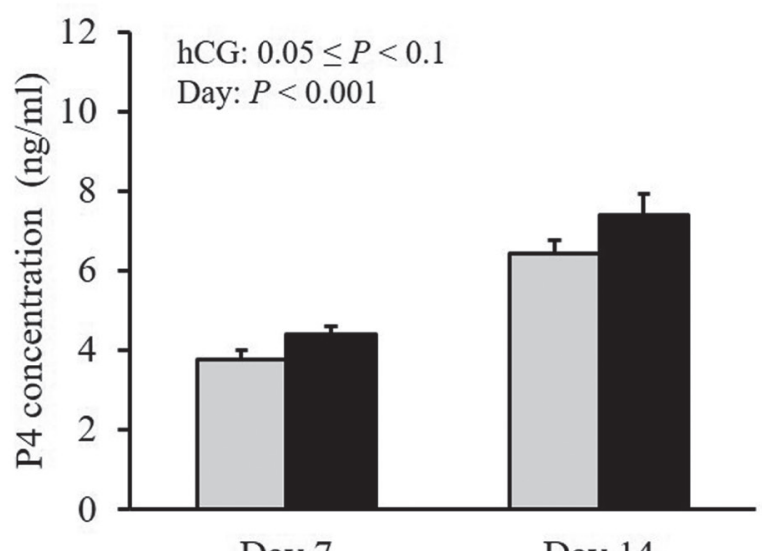

B

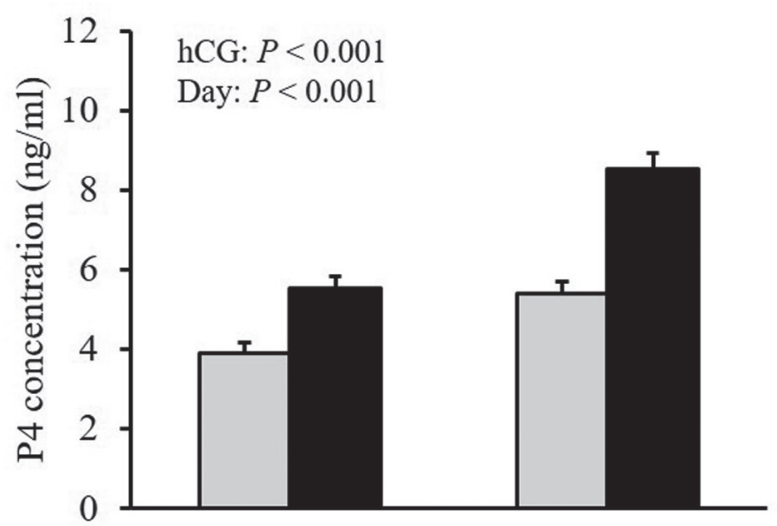

Day 7

Day 14

Fig. 5. Plasma progesterone concentration on days 7 and 14 in the hCG-treated ipsilateral (A) and contralateral (B) groups. P4, progesterone; hCG, human chorionic gonadotropin.

\section{口Ipsilateral Contralateral}

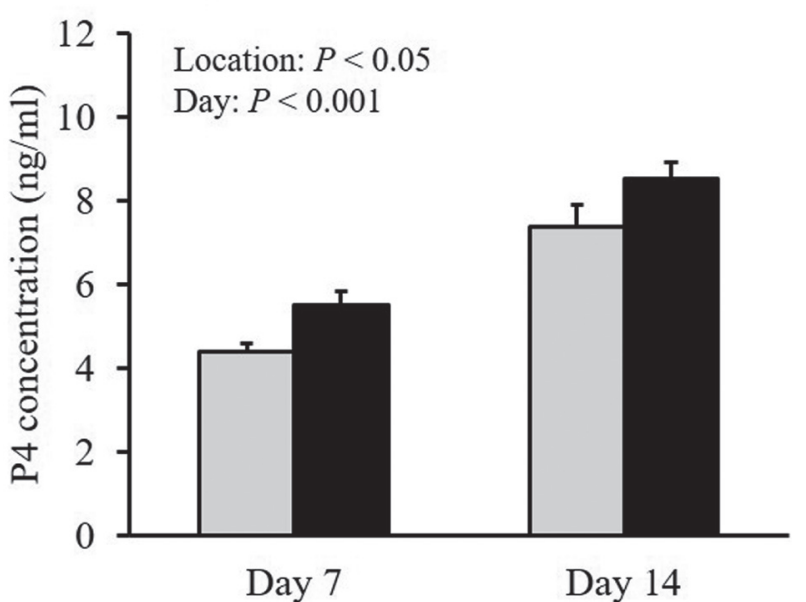

Fig. 6. Plasma progesterone concentration in the hCG treated ipsilateral and contralateral groups. P4, progesterone. $\square$ No treatment $\mathbf{a C G}$

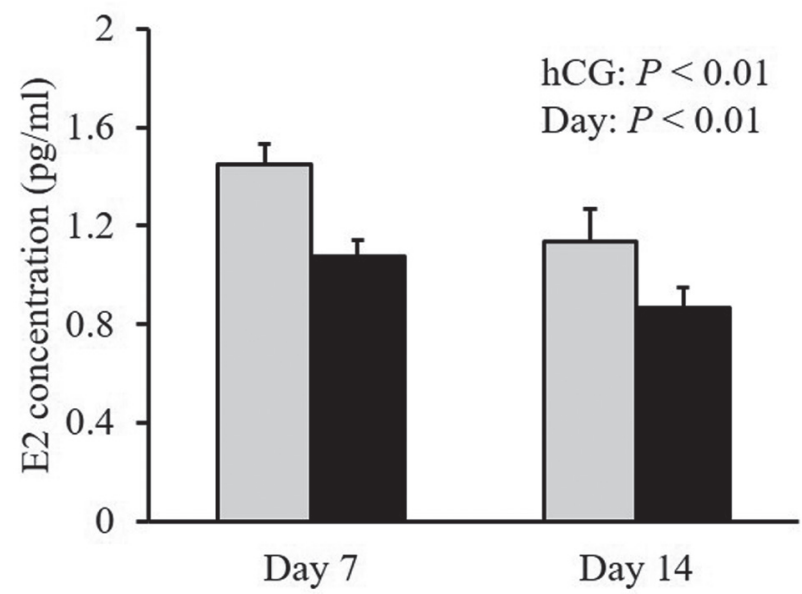

Fig. 7. Plasma estradiol concentration on days 7 and 14 in the hCG-treated and untreated heifers, without distinction between the ipsilateral and contralateral groups. E2, estradiol.

Contralateral heifers that were administered hCG on day 5 had larger original CL diameters on day 7 and higher plasma P4 concentration on days 7 and 14, compared with untreated heifers. A previous report indicated that hCG administration on day 5 post-estrus increases the original CL tissue area, induces accessory CL formation, and increases plasma P4 concentration from day 7 in cross-bred beef heifers [18]. However, hCG administration did not alter the original CL diameter and only slightly increased plasma P4 concentration in the ipsilateral group. hCG administration promotes original CL development and function. Even when no accessory CL is formed, plasma P4 concentration increases in response to hCG administration in heifers [4, 9] and dairy cows [20]. These studies demonstrate that the positive effects of hCG administration on bovine plasma P4 concentration are the result of improved original CL function and accessory CL formation. The present study showed that the accessory CL was similar in diameter in the ipsilateral and contralateral groups on day 14. Thus, the difference between the ipsilateral and contralateral groups, in terms of the effects of hCG treatment on original CL development and function, influenced plasma P4 concentration. However, we were unable to determine why the effects of hCG administration on original CL development and function differed between the ipsilateral and contralateral groups. A previous study showed that ovarian blood perfusion increases when CL and W1DF occurr in the same ovary. In contrast, when the distance between the CL and W1DF walls exceeds $2.0 \mathrm{~mm}$ on day 5, the CL and W1DF diameters decrease [8]. The CL and W1DF may compete for blood flow in the ovary, resulting in the suppression of mutual CL and W1DF development. In the present study, the distances between the ovarian structures may have influenced the effects of hCG on 
original CL development and function and intraovarian blood flow, depending on the locational relationships between the original $\mathrm{CL}$ and the W1DF/accessory CL. Measurement of the distance between the original CL and the W1DF/accessory CL, and the blood flow of each ovarian structure, before and after hCG treatment, are necessary to test this hypothesis.

Our results showed that hCG administration significantly decreased plasma E2 concentration on days 7 and 14, regardless of the locational relationship between the original CL and W1DF. A previous study showed that inducing ovulation in the W1DF with hCG decreases plasma E2 concentration in Japanese black beef cattle [15]. Removal of the E2-producing W1DF by inducing ovulation may have decreased plasma E2 on day 7. Moreover, an increase in plasma P4 concentration suppresses pituitary LH secretion and decreases follicle development and function [3]. In the present study, hCG administration significantly increased plasma P4 concentration in the contralateral group and slightly increased it in the ipsilateral group, respectively. For heifers administered hCG, elevated plasma P4 concentration may have suppressed follicular function, thereby lowering plasma E2 concentration on day 14, compared with untreated heifers.

High plasma P4 concentration in the early luteal phase promotes fertility in lactating [23] and non-lactating cows [10]. In contrast, high plasma E2 concentration after ovulation inhibits bovine embryonic development [2]. Moreover, a decrease in plasma E2 concentration during the luteal phase, induced by hCG [15] or GnRH [11], improves fertility in beef and dairy cattle. Here, we observed high plasma P4 concentration and low plasma E2 concentration in heifers treated with hCG. Plasma P4 concentration was higher in the hCG-treated contralateral group than untreated heifers and those in the ipsilateral group treated with hCG. Hence, heifers in the hCG-treated contralateral group may have acquired an endocrine environment that was more suitable for embryonic development than those in the other groups. In contrast, this result conflicted with the results reported by Miura et al. [12], who found that hCG administration on day 5 post-AI improves the conception rate in ipsilateral, but not contralateral, dairy cows. However, our sample size was too small to interpret the outcomes regarding ET conception rate. To evaluate the effects of hCG treatment on ET conception rate, an additional study with a larger sample size is necessary. In addition, we used only one breed, cross-bred beef heifers (Japanese black $\times$ Holstein), in the present study and thus, our findings may be limited to a certain cattle breed. Further investigations are required to determine whether these findings are commonly replicated in other cattle breeds, such as dairy cows.

In summary, the administration of hCG to cross-bred heifers on day 5 post-ovulation induced W1DF ovulation and accessory CL formation and decreased plasma E2 concentration. Moreover, hCG treatment more significantly promoted CL development and increased plasma $\mathrm{P} 4$ concentration in the contralateral group than in the ipsilateral group. This study provides new evidence that the effect of hCG on bovine ovarian function is influenced by the location of the CL and W1DF. Future studies should examine whether the different effects of hCG on plasma P4 concentration between the ipsilateral and contralateral groups affects fertility in cattle.

ACKNOWLEDGMENT. The authors thank the owner and employees of Fukuzawa Farm, Kamishihoro-cho, Hokkaido, Japan, for their cooperation and the use of their ET-recipient heifers in our experiments.

\section{REFERENCES}

1. Abedel-Majed, M. A., Romereim, S. M., Davis, J. S. and Cupp, A. S. 2019. Perturbations in lineage specification of granulosa and theca cells may alter corpus luteum formation and function. Front. Endocrinol. (Lausanne) 10: 832. [Medline] [CrossRef]

2. Ayalon, N. 1978. A review of embryonic mortality in cattle. J. Reprod. Fertil. 54: 483-493. [Medline] [CrossRef]

3. Bergfeld, E. G., Kojima, F. N., Cupp, A. S., Wehrman, M. E., Peters, K. E., Mariscal, V., Sanchez, T. and Kinder, J. E. 1996. Changing dose of progesterone results in sudden changes in frequency of luteinizing hormone pulses and secretion of 17 beta-estradiol in bovine females. Biol. Reprod. 54: 546-553. [Medline] [CrossRef]

4. Chagas e Silva, J. and Lopes da Costa, L. 2005. Luteotrophic influence of early bovine embryos and the relationship between plasma progesterone concentrations and embryo survival. Theriogenology 64: 49-60. [Medline] [CrossRef]

5. Echternkamp, S. E. and Hansel, W. 1973. Concurrent changes in bovine plasma hormone levels prior to and during the first postpartum estrous cycle. J. Anim. Sci. 37: 1362-1370. [Medline] [CrossRef]

6. Galvão, K. N., Santos, J. E., Coscioni, A. C., Juchem, S. O., Chebel, R. C., Sischo, W. M. and Villaseñor, M. 2006. Embryo survival from gossypolfed heifers after transfer to lactating cows treated with human chorionic gonadotropin. J. Dairy Sci. 89: 2056-2064. [Medline] [CrossRef]

7. Ginther, O. J., Knopf, L. and Kastelic, J. P. 1989. Temporal associations among ovarian events in cattle during oestrous cycles with two and three follicular waves. J. Reprod. Fertil. 87: 223-230. [Medline] [CrossRef]

8. Ginther, O. J., Rakesh, H. B. and Hoffman, M. M. 2014. Blood flow to follicles and CL during development of the periovulatory follicular wave in heifers. Theriogenology 82: 304-311. [Medline] [CrossRef]

9. Maillo, V., Duffy, P., O'Hara, L., de Frutos, C., Kelly, A. K., Lonergan, P. and Rizos, D. 2014. Effect of hCG administration during corpus luteum establishment on subsequent corpus luteum development and circulating progesterone concentrations in beef heifers. Reprod. Fertil. Dev. 26: 367-374. [Medline] [CrossRef]

10. Mann, G. E. and Lamming, G. E. 2001. Relationship between maternal endocrine environment, early embryo development and inhibition of the luteolytic mechanism in cows. Reproduction 121: 175-180. [Medline] [CrossRef]

11. Mann, G. E., Lamming, G. E. and Fray, M. D. 1995. Plasma oestradiol and progesterone during early pregnancy in the cow and the effects of treatment with buserelin. Anim. Reprod. Sci. 37: 121-131. [CrossRef]

12. Miura, R., Matsumoto, N., Izumi, T., Kayano, M., Haneda, S. and Matsui, M. 2018. Effects of human chorionic gonadotropin treatment after artificial inseminations on conception rate with the first follicular wave dominant follicle in the ovary ipsilateral to the corpus luteum in lactating dairy cows. J. Reprod. Dev. 64: 485-488. [Medline] [CrossRef]

13. Miyamoto, A., Okuda, K., Schweigert, F. J. and Schams, D. 1992. Effects of basic fibroblast growth factor, transforming growth factor-beta and 
nerve growth factor on the secretory function of the bovine corpus luteum in vitro. J. Endocrinol. 135: 103-114. [Medline] [CrossRef]

14. Nascimento, A. B., Bender, R. W., Souza, A. H., Ayres, H., Araujo, R. R., Guenther, J. N., Sartori, R. and Wiltbank, M. C. 2013. Effect of treatment with human chorionic gonadotropin on day 5 after timed artificial insemination on fertility of lactating dairy cows. J. Dairy Sci. 96: $2873-2882$. [Medline] [CrossRef]

15. Nishigai, M., Kamomae, H., Tanaka, T. and Kaneda, Y. 2002. Improvement of pregnancy rate in Japanese Black cows by administration of hCG to recipients of transferred frozen-thawed embryos. Theriogenology 58: 1597-1606. [Medline] [CrossRef]

16. Price, C. A. and Webb, R. 1989. Ovarian response to hCG treatment during the oestrous cycle in heifers. J. Reprod. Fertil. 86: 303-308. [Medline] [CrossRef]

17. Rantala, M. H., Mutikainen, M., Schuler, G., Katila, T. and Taponen, J. 2014. Endometrial expression of progesterone, estrogen, and oxytocin receptors and of 20 $\alpha$-hydroxysteroid dehydrogenase and cyclooxygenase II 2 and 5 days after ovulation in induced short and normal estrous cycles in dairy cows. Theriogenology 81: 1181-1188. [Medline] [CrossRef]

18. Rizos, D., Scully, S., Kelly, A. K., Ealy, A. D., Moros, R., Duffy, P., Al Naib, A., Forde, N. and Lonergan, P. 2012. Effects of human chorionic gonadotrophin administration on day 5 after oestrus on corpus luteum characteristics, circulating progesterone and conceptus elongation in cattle. Reprod. Fertil. Dev. 24: 472-481. [Medline] [CrossRef]

19. Sánchez, J. M., Mathew, D. J., Passaro, C., Fair, T. and Lonergan, P. 2018. Embryonic maternal interaction in cattle and its relationship with fertility. Reprod. Domest. Anim. 53 Suppl 2: 20-27. [Medline] [CrossRef]

20. Sánchez, J. M., Randi, F., Passaro, C., Mathew, D. J., Butler, S. T. and Lonergan, P. 2018. Effect of human chorionic gonadotrophin administration 2 days after insemination on progesterone concentration and pregnancy per artificial insemination in lactating dairy cows. J. Dairy Sci. 101: 6556-6567. [Medline] [CrossRef]

21. Torres, A., Chagas E Silva, J., Diniz, P. and Lopes-da-Costa, L. 2013. Evaluation of treatments with hCG and carprofen at embryo transfer in a demi-embryo and recipient virgin heifer model. Animal 7: 1317-1322. [Medline] [CrossRef]

22. Wallace, L. D., Breiner, C. A., Breiner, R. A., Spell, A. R., Carter, J. A., Lamb, G. C. and Stevenson, J. S. 2011. Administration of human chorionic gonadotropin at embryo transfer induced ovulation of a first wave dominant follicle, and increased progesterone and transfer pregnancy rates. Theriogenology 75: 1506-1515. [Medline] [CrossRef]

23. Wiltbank, M. C., Souza, A. H., Carvalho, P. D., Cunha, A. P., Giordano, J. O., Fricke, P. M., Baez, G. M. and Diskin, M. G. 2014. Physiological and practical effects of progesterone on reproduction in dairy cattle. Animal 8 Suppl 1: 70-81. [Medline] [CrossRef] 